\title{
Classification of Dynamic Cartographic Symbols applied to Augmented Reality (AR) Systems
}

\author{
Fabrício Rosa Amorim ${ }^{\mathrm{a}, *}$, Marcio Augusto Reolon Schmidt ${ }^{\mathrm{a}}$ \\ ${ }^{a}$ Programa de Pós-Graduação em Ciências Geodésicas, Universidade Federal do Paraná -UFPR, Curitiba -PR, Brazil \\ fabricioamorimeac@hotmail.com, marcio.schmidt@gmail.com \\ * Corresponding author
}

\begin{abstract}
Paper maps were widely used during centuries; however, these maps do not change dynamically regarding its use context, the user behaviour and the change in the representations through time. Considering the research related to digital cartography, maps started to be seen both digitally and in a dynamic way due to the application of static and dynamic visual variables. During the process of navigation supported by maps, the comprehension of certain cartographic symbols can be a complex task for people. When using representations for virtual environment, specifically the Augmented Reality (AR) and Virtual Reality (VR), an advantage is the complementing of the information communication through virtual objects, which reduces the cognitive effort to decode all the representation as in the traditional maps. Until now, several scientific investigations about adjusting the cartographic design aimed to personal and vehicular navigation maps in AR are being developed. However, few studies investigate the application of dynamic symbols in AR built from the dynamic visual variables of Cartography. In this way, the aim on this research is to classify the symbols that use the dynamic variables. In addition, verify the presence of these variables in Augmented Reality systems in mobile devices that use AR to represent spatial information in the context of personal navigation in an outdoor environment.
\end{abstract}

Keywords: navigation, digital maps, dynamic variables, augmented reality (AR).

\section{Introduction}

Dynamic maps are also called maps with visual animations, to emphasize its difference in relation to static maps (Kraak; Brown, 2001). These maps are the consequence of the technological advance applied to cartography (Slocum et al., 2009). Still, they can be characterized by the continuous change in the presentation of phenomenon's over time and/or space (Peterson, 1995). Thus, cartography categorizes dynamic maps in temporal and non-temporal (Peterson, 1995; Kraak, 1999). Dynamic temporal maps represent variations of attributes and feature locations on the map over time translated by the successive time transformations. On non-temporal maps, the dynamism of the phenomenon manifests through transformations of shape, position, among other visual variables (Peterson, 1995).

The literatures regarding the dynamic symbols can the categorized in two groups, design and evaluation (Blok; Köbben, 1998; Harrower, 2007). The design of the map symbols involves the definition of dynamic and static variables, besides the ones with visual animation and interaction (Dibiase et al., 1992). The evaluation of dynamic maps may consider the evaluation of tools, the comparison of methods and the cognitive approach (Blok; Köbben, 1998; Harrower, 2007).

Several researchers point the need to evaluate the efficiency of dynamic maps, as well as questions of visual attention (Griffin et al., 2006; Harrower, 2007). For this purpose, different types of dynamic representations include different manifestations of change. In studies of Griffin et al. (2006), readers answered faster and identified more correct patterns when using dynamic maps than when using static maps. According to Xiaofang et al. (2014), maps with animated and interactive functions can be more efficient than printed maps (static). This way, users can perceive the dynamic visual sense of the map's feature, which can move to a spatial direction and/or its attribute can be transformed with the use of visual variables.

Contrary to the results obtained by Griffin et al. (2006) and Xiaofang et al. (2014), to Opach et al. (2014), since the information shown in the dynamic components cause changes over time, users tend to spend more time looking at them, in comparison with the static component, in which the information is fixed. The discrepancies found in these studies can be explained by unequal and non-equivalent content of information during the experiment; interactivity levels of the user with the dynamic map; the possibility of 
controlling the rhythm of the animation sequence ; the reader's task ; if the animation was consistent with the process that intended to transmit. With the increase of usage of dynamic maps, it is required a deeper investigation about the processing of this type of visual information (Griffin et al., 2006; Harrower; Fabrikant; Goldsberry, 2008; Berney; Bétrancourt; 2016).

Augmented reality (AR) can be defined as the mix of the real environment and virtual object's sensorial perception, being possible to immerse and interact in a natural way with the natural environment and the virtual objects, aiming to improve the senses and abilities of its users (Azuma et al., 2001; Bobrich; Otto, 2002; Kán; Kaufmann, 2012). According to Azuma et al. (2001), three basic characteristics of computing systems provided of augmented reality can be pointed: virtual elements and real environment combined; real time interactivity and processing; and to be conceived in three dimensions.

Not only the AR exhibition system is dynamic by involving the constant change of scenarios for the user, but also the available symbols in AR can be dynamic. Among many aspects, this paper will approach the classification and perception of the visual variables used in cartography. For this purpose, three systems of Augmented Reality were used to verify which dynamic variables were present in these systems. The chosen systems were the Google Maps AR (Google Maps, 2021), the Maps AR (Maps, 2021) and the AR GPS Drive/Walk Navigation (AR GPS Drive/Walk Navigation, 2021). All these AR systems are compatible with the Android system and can be used at no charge after its download in the official repository.

\section{Visual Perception of Dynamic Symbols}

Dynamic map production may consist of the sequential reproduction of images to create a film, process called as "flip-book" (Harrower, 2004). A second approach regarding the production of these maps can be presented by displays, in a smooth way and with more options of project. Its design consists in specifying numerically the appearance of dynamic objects (e.g.: size, direction and speed) (Harrower, 2004). From the point of view of design, literature regarding the dynamic maps recommends the use of smooth transitions in opposition to the "flip-book" (Lobben, 2003; MacEachren; Dibiase, 1991).

The human visual system is capable of notice, track and foresee the movement. The movement of a symbol can be noticed only if its speed remains within a specific range of values whose system is sensible to. If it is too fast, it will difficult be visually noticed. Thus, the speed of the presentation must be slowed down so that the movement (capture) is visible. However, it is possible that the movement itself is not attracting the attention, but the detection of a new object in the visual field (Hillstrom; Yantis, 1994).

For Dukaczewski (2014), some perceptive factors can be observed during the design of dynamic maps, such as: small periodic movements are usually better signs than colours or shapes in all visual field; movements with small visual amplitudes are highly detectable, while small amplitudes can present a slower time of reaction; slow linear movements can be detected with good precision, good response time and are not considered intrusive or distracting; update rates between 20 and 30 frames per minute are sufficient to induce the continuous movement perception (for "flip-book representations). Woods (1995) defined required criteria during the production of dynamic representations, especially to support the control and direction of human's attention. These criteria are related to notions of accessibility in projects; provision of partial information in the interface; and cautions for the user's mental economy while reading the visual representations without excessive cognitive effort.

According to studies by Mayer (2002), the speed of dynamic symbols' presentation can affect the cognitive processing of the dynamic information. Therefore, a high speed of presentation may enhance global events (that is, macro events), while slow speeds may enhance local events (that is, local events). Although, according to the authors, the movement's perception appeared to be affected mainly by its content, and not by the speed of presentation.

According to Wickens et al. (2004), the required attention to observe moving objects in the visual periphery may increase cognitive load or stress level to the observer. The reader's cognitive effort can be reduced when some recommendations are adopted (Mayer e Moreno, 2003), such as: unload the excess of perceptive visual work when possible; segment the content through breaks; include pretraining to the users; eliminate material that can be harmful to the visual perception such as complex transition; highlight the most important symbols via figurebackground segregation techniques; approximate in a temporal and/or spatial way the related contents; eliminate, when possible, the redundant information like those presented through texts and sounds; pay attention to cognitive characteristics for each user group.

The visual perception of static and dynamic symbols in maps can be examined through the ocular tracking, statistic metrics or general data collection during experiments. Overall, the following cognitive evaluations can be used to examine the visual perception of static and dynamic symbols: visual fixation of symbols; usability evaluation; qualitative surveys/questionnaires (Wickens et al., 2004; 
Iida, 2005; Poole et al., 2005; Pugliesi et al., 2013; Krassanakis, 2013). On visual fixation of symbols, six metric statistics have been considered in the analysis of each visual scene (Krassanakis et al., 2013). These metrics are based on measures of eye-tracking (the capture of the movements of the eyes), which include success metric (detection); duration metric (efficiency); percentage of duration metric (average percentage of required duration), number metric (mean number of fixations), percentage of fixation metric (mean percentage of the number of fixations), time until the first fixation (indicates the mean value of duration) (Poole et al., 2005; Liao et al., 2017).

\subsection{Classification of Dynamic Symbols}

The project of dynamic maps can consider the aspect of the dynamic graphic variables defined by DiBiase et al. (1992) and MacEachren (1995), as well as considering the variables with visual animation mentioned by Peterson (1995). Although there is a difference to designate these variables, it is understood that its meanings are similar. The synthesis of dynamic variables can be found in some research in cartography, such as the ones found in Peterson (1995), Dibiase et al. (1992), MacEachren (1995), Kraak (1999) and Blok (1999).

Peterson (1995):

- Size: change in the dimension of the symbol caused by changes in the attribute's value;

- Shape: change in the way that symbol is presented;

- Position: change in the location of the symbol;

- Speed: change in the speed caused by the change range/interval;

- Point of view: can be used to highlight or retreat a representation;

- Distance: change in the scale;

- Scene: disappearance, mixing and smoothing effects, to indicate transition;

- Texture, pattern, hatching and colour: use of graphic visual variables.

Dibiase et al. (1992):

- Duration: associated to the number of units of time that a scene can be seen;

- Change interval: proportion of magnitude of change in position (and attributes) between scenes, split by the duration of each scene;

- Order: chronological order in which the scenes are screened.

MacEachren (1995):

- Moment in time: date in which the change in time occurs;
- Frequency: number of times that a phase (scene) is repeated in a series of changes in space in relation to a time unit;

- Synchronization: patterns of symbols that move at the same time and in an orderly manner.

Kraak (1999):

- Places: use of the variable(s) with position and/or speed visual animation;

- Attributes: use of the variable(s) with the texture, pattern, colour and hatching visual animation;

- Exhibition time: it is related to the moment which the reader observers the symbol, it can also be related to the change in time or date of the information that is exhibited on the display.

Blok (1999):

- Appearance/disappearance: existence or non existence of an object;

- Mutation: change in the thematic attribute;

- Movement: change in the location or position.

The classifications proposed by these authors are directly related between themselves. For this purpose, it is possible to indicate that some dynamic variables proposed by a certain author correspond to other variables, classified by other authors. In this paper, it is proposed a new categorization of the dynamic visual variables, based on the considerations of the studied authors, as follow:

- Duration: associated to the number of units of time that a scene can be visualized;

- Frequency: number of times that a phase (scene) is repeated in relation to a unit of time;

- Order: chronological sequence in which the scenes are shown;

- Position: change in location/coordinate of the symbol;

- Point of view: change in the symbol's location on the screen, can be used to highlight or retreat a representation;

- Distance: change in the scale;

- Scene: effects of transition by disappearance, mixture and smoothing, existence or not of an object or scene;

- Attributes: change in the thematic attribute, usage of visual graphic variables texture, pattern, colour, shape, size;

- Moment in time: date in which the change in time occurs or moment in which the reader observes the symbol;

- Synchronization: patterns of symbols that move at the same time and in an orderly manner. 


\section{Cartographic Applications with the Use of Augmented Reality Systems}

The Augmented Reality (AR) applied to Cartography may increase the interactivity in geographic visualization, once this tool has the capacity to provide a learning environment, where the user visualizes information in an effective way, over geographic surfaces that improve the effectiveness of multimedia presentations (Asai et al., 2008).

In cartography, several research involving $\mathrm{AR}$ are described for the most diverse applications, such as: visualization of collision between real and virtual objects (Aliaga, 1997); supporting drivers in dangerous roads (Scott-Young, 2003); visualizing interest points in traditional 2D maps (topographical charts) (Bobrich; Otto, 2002); in urban turism with the help of transparent HMD glasses and navigation from GPS positioning (Grohs; Maestri, 2002); in a collaborative GIS (Geographical Information System) environment to visualize height data ( (SRTM - Shuttle Radar Topograph Mission) (Hedley et al., 2002); using the Augmented Reality tracking (AR tracking) technology when projecting a map in a surface (e.g.: table) to manipulate the information with the hands without the need of using a mouse or keyboard (Sheldon; Hedley, 2002); in the projection of information of a certain region over a physical model (Ratti et al., 2004); on direct insertion of three-dimension models in images captured in an environment such as support to field survey, with the help of a GPS (Centeno et al., 2004; Centeno; Kishi, 2006; Centeno et al., 2009); on visualizing information about the mapping of Great Britain (Radburn, 2006); on obtaining properties measurements (Dunston; 2009); on describing touristic points (Linaza et al.; 2012; Yovcheva et al., 2014; Cranmer et al., 2018; Han et al., 2018); on the management of emergencies of a mixed reality, which demonstrated virtual evacuation simulations to environments built in real world (Lochhead; Hedley, 2019); on the use of UAV's (Chakrabarty et al., 2016; Rohan et al., 2019); applied to games (Rauschnabel et al., 2017; Laine, 2018).

\subsection{Characterization of dynamic variables in Augmented Reality (AR) Interfaces used for navigation}

Several cartographic systems have become useful tools to define and indicate routes, used during navigation tasks for both indoor and outdoor environments (Nikander et al., 2013; Epstein et al., 2017). Aiming to analyse the use of dynamic symbols in AR oriented to navigation, three systems were selected to support the research, among them Google Maps AR (Figure 2), Maps AR (Figure 3) and AR GPS Drive/Walk Navigation (Figure 4). These systems were selected for presenting the function of selection and projection of routes, display of routes through symbols in AR interface and for presenting dynamic symbols in its graphic projects.

For the three systems used in this research, the task of tracing routes was accomplished during an experiment. The selection of route consisted in selecting two places located approximately $200 \mathrm{~m}$ one from another, possible of being connected by a straight line, in other words, without the necessity of realizing curves during a route. For visualizing the scenarios, the Smartphone with the AR system already initialized was positioned between the beginning and end of the route. These points are located in a test area located at Federal University of Paraná - UFPR, in the city of Curitiba - PR. The test area was separated in three scenarios, simulating the steps of a route during the navigation process, being the start, middle and end of the route (Figure 1). A video with the screen recordings during the experiments can be found on: https://www.youtube.com/watch?v=KydIiTCk97o.

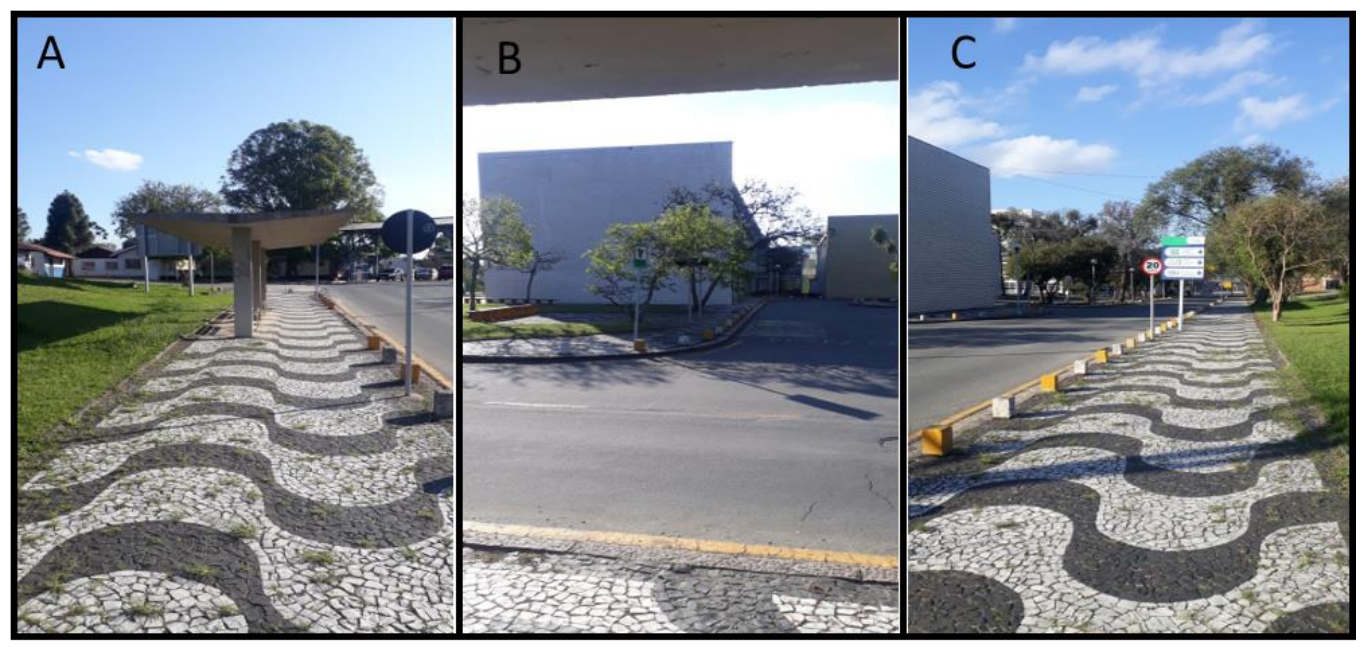

Figure 1. Scenarios of the test area: start/beginning (a), middle (b) and end (c). 


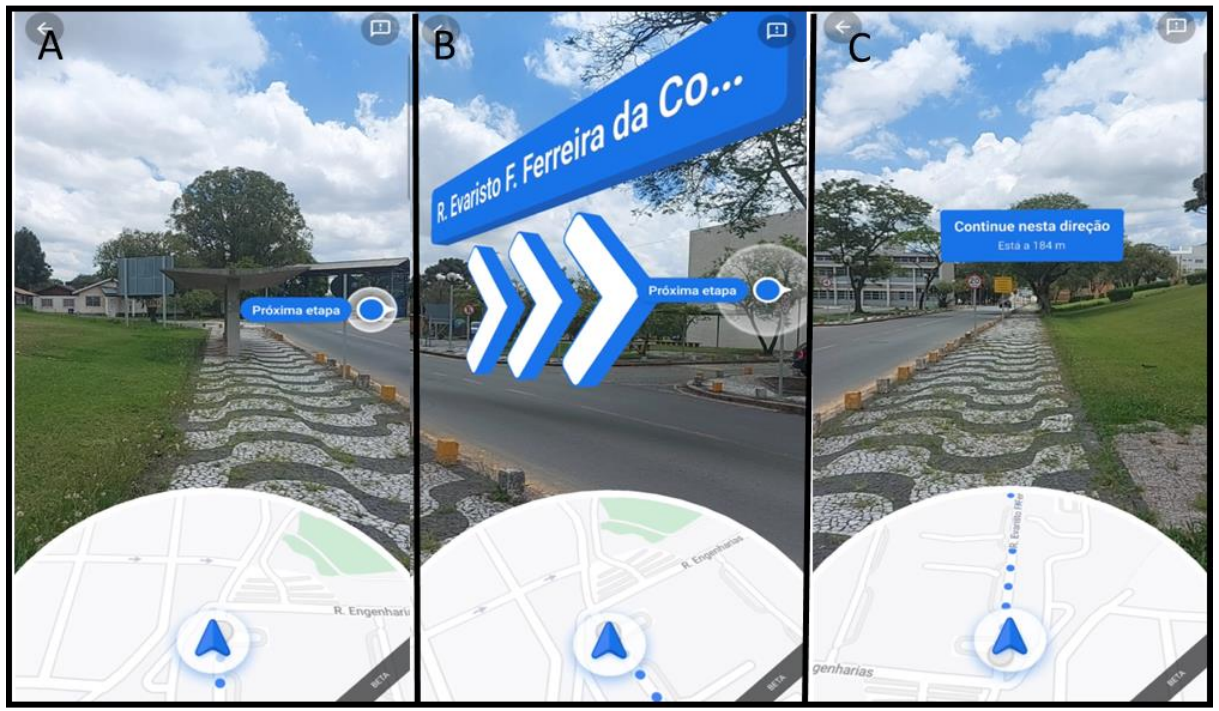

Figure 2. Screenshots of the Google Maps AR system for the scenarios: start/beginning (a), middle (b) and end (c).

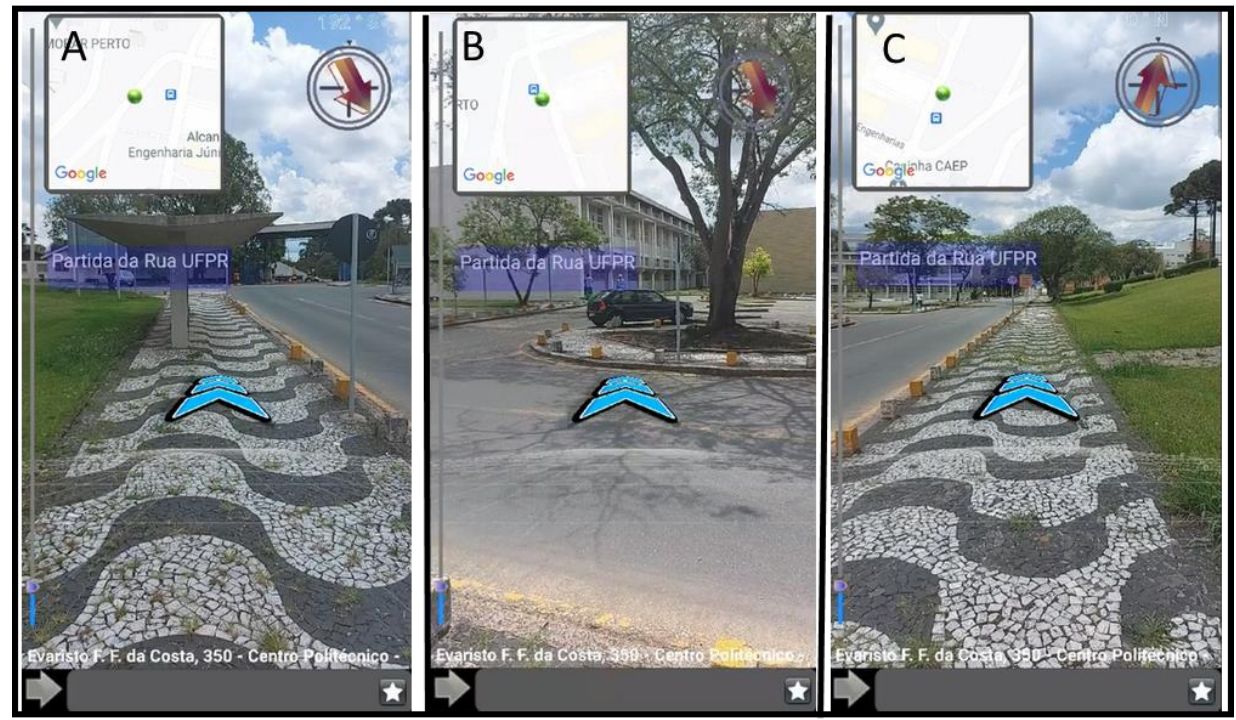

Figure 3. Screenshots of the Maps AR system for the scenarios: start/beginning (a), middle (b) and end (c).

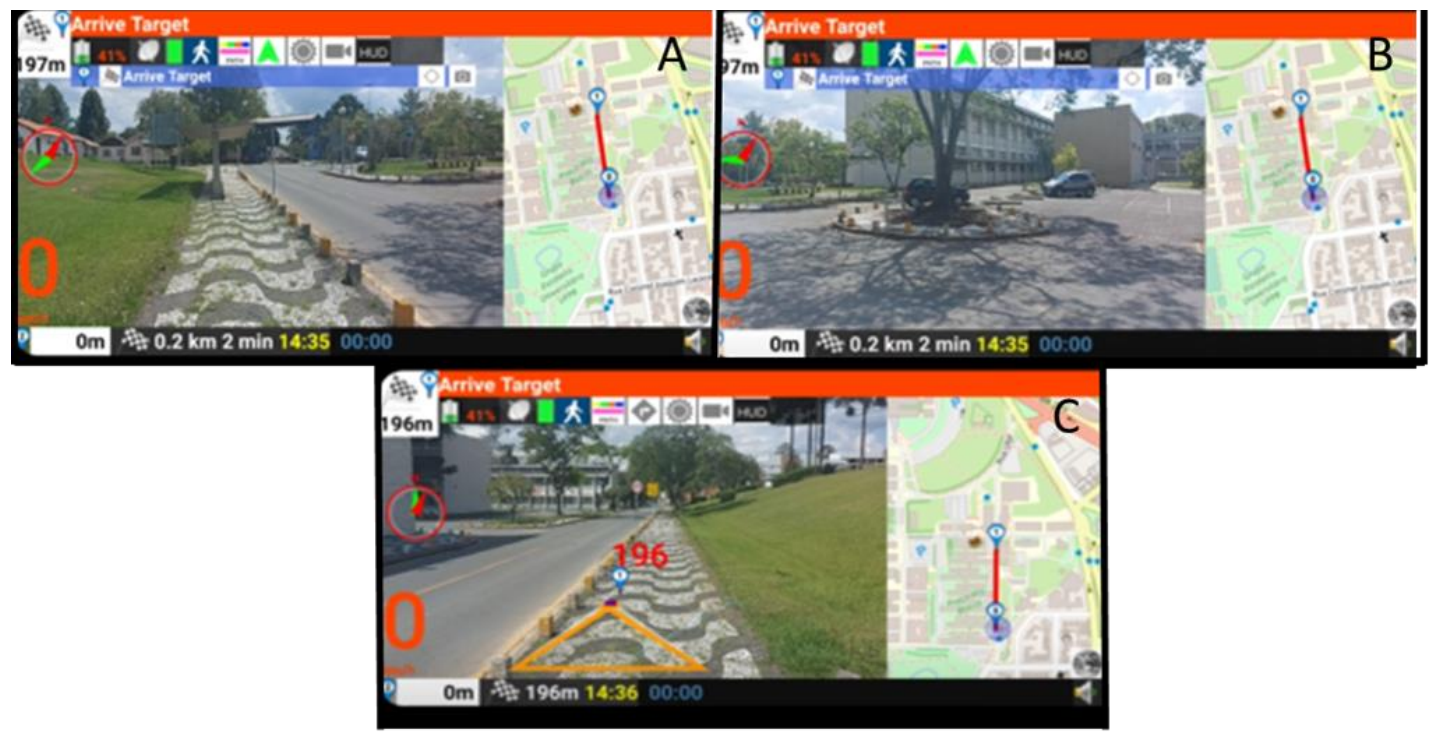

Figure 4. Screenshots of the AR GPS Drive/Walk Navigation system for the scenarios: start/beginning (a), middle (b) and end (c). 


\section{Use of the Dynamic Symbols in the evaluated} ARS

To evaluate the use of the dynamic symbols in the ARS chosen for this research, the dynamic visual variables were previously grouped (Chapter 3 ) and the presence/absence of these symbols was marked on Chart 1. In this step, were considered the $2 \mathrm{D} / 3 \mathrm{D}$ symbols projected in the $\mathrm{AR}$ interfaces and were not considered the own ARS intrinsic dynamic properties, such as change in the scenario ("scene" dynamic visual variable) captured by the smartphone camera.

In Google's maps, Google Maps AR, it is possible to see a change in the point symbol used to indicate that it is needed to change the scene (Figure 2a), in other words, to indicate the correct orientation to go through the route. There is a synchronization effect to increase the size of the white part (border) of the blue symbol. In figure $2 b$, it is possible to notice that the blue arrows change in size, but are constant over time, therefore, are static. Both the blue arrow and the street name are static, their position is fixed according to a certain location (predefined coordinate when plotting the route). Figure $2 \mathrm{c}$ is shown to the user when the correct route orientation is reached. The blue symbol with its white sync border disappears from the screen and appears a message to the user to continue the route direction. In this moment, the map located at the bottom of the screen changes orientation as the user rotates the smartphone horizontally $\left(0\right.$ to $\left.360^{\circ}\right)$.

In Maps AR system, the change occurs in the compass' arrow, as it can be noticed in Figure 3. Therefore, the symbol dynamism can be classified as change in the position dynamic variable (orientation). The map's orientation is changed as the user rotates the smartphone horizontally. It is possible to notice that the blue arrows change their size, but are constant over time, thus, are static.

The AR GPS Drive / Walk Navigation system was presented in Figure 4. It is noticeable the change in orientation in the green arrow located on the compass. To represent the change in the value of the user's speed over the route, besides the change in the distance between the start and end point of the route, the dynamic visual variable used is attribute (shape).

\begin{tabular}{|c|c|c|c|}
\hline \multirow{2}{*}{ Dynamic Variables } & \multicolumn{3}{|c|}{ ARS } \\
\hline & Google Maps AR & Maps AR & AR GPS Drive \\
\hline Duration & $\checkmark$ & & $\checkmark$ \\
\hline Frequency & $\checkmark$ & $\checkmark$ & $\checkmark$ \\
\hline Order & $\checkmark$ & & $\checkmark$ \\
\hline Position & & & \\
\hline Speed & $\checkmark$ & & $\checkmark$ \\
\hline Point of View & & & $\checkmark$ \\
\hline Distance & $\checkmark$ & & \\
\hline Scene & $\checkmark$ & & \\
\hline Attributes & $\checkmark$ & & \\
\hline Moments in time & $\checkmark$ & & \\
\hline Synchronization & & & \\
\hline
\end{tabular}

Table 1. Use of Dynamic Symbols in ARS.

\section{Final Considerations}

From the analysis accomplished in this research, it was possible to notice the wide use of dynamic symbols in AR applications. More specifically, dynamic symbols used to represent route information in navigation processes. Through the comparative analysis between the selected systems, it was identified that the apps do not include even half of the existing visual variables for the creation of a visualization with dynamic symbols. These technological difficulties are presented today as a great impasse to the development of three-dimensional visualizations in perspective with the ability to communicate spatial information in a similar way to what is done by conventional maps. Thus, in the continuity of this research, we are discussing the adaptation of visual variables in view of technological limitations in order to circumvent these problems for users of 3D representations.

\subsection{Acknowledgements}

To National Council for Scientific and Technological Development $(\mathrm{CNPq})$ for the financial support for conducting the research, process No. 142253 / 2020-0. 


\section{References}

Aliaga, D. G. Virtual objects in the real world. Communications of the ACM, v. 40, n. 3, p. 4954, 1997.

AR GPS Drive/Walk Navigation. PlayStore . Available at: https://play.google.com/store/apps/details?id=com.w.arg ps. Access in fev., 2021.

Asai, Y.; Guha, A.; Villa, A. E. P. Deterministic neural dynamics transmitted through neural networks. Neural Networks, v. 21, n. 6, p. 799-809, 2008.

Azuma, R.; Baillot, Y.; Behringer, R.; Feiner, S.; Julier, S.; MacIntyre, B. Recent advances in augmented reality. IEEE computer graphics and applications, v. 21, n. 6, p. 34-47, 2001.

Berney, S.; Bétrancourt, M. Does animation enhance learning? A meta-analysis. Computers \& Education, v. 101, p. 150-167, 2016.

Blok, C. Monitoring Change: Characteristics of Dynamic Geospatial Phenomena for Visual Exploration. In: International Cartographic Association - ICA, 19., Ottawa, Canadá, Aug. 1999.

Blok, C.; Köbben, B. A Web Cartography Forum: an evaluation site for visualization tools, 1998.

Bobrich, J.; Otto, S. Augmented maps. International Archives of Photogrammetry Remote Sensing and Spatial Information Sciences, v. 34, n. 4, p. 502-505, 2002.

Centeno, J., Gonçalves, M. G. A., Abreu, E. A. F. C. S., \& de Castro Pedro, E. C. P. Experimento de Fusão de Dados em Realidade Aumentada. Universidade Federal do Paraná. 2004.

Centeno, J. A. S.; Kishi, R. T.; Mitishita, E. A. Threedimensional data visualization in water quality studies using augmented reality. In: Proceedings of the 6th International Symposium on Mobile Mapping Technology. 2009.

Centeno, J. A. S.; Kishi, R. T. Uso de Realidade Aumentada como suporte para a visualização de dados em estudos de qualidade de água. 2006.

Chakrabarty, A., Morris, R., Bouyssounouse, X., Hunt, R. Autonomous indoor object tracking with the Parrot AR. Drone. In: 2016 International Conference on Unmanned Aircraft Systems (ICUAS). IEEE, 2016. p. 25-30.

Cranmer, E. E.; Tom Dieck, M. C.; Jung, T. How can tourist attractions profit from augmented reality? In: Augmented reality and virtual reality. Springer, Cham, 2018. p. 21-32

Dibiase, D.; MacEachren, A. M.; Krygier, J. B.; Reeves C. Animation and the Role of Map Design in Scientific
Visualization, Cartography and Geographic Information Systems, p. 201-214, 1992.

Dukaczewski, D. R. Designing Simple and Complex Animated Maps for Users from Different Age Groups, Employing the Appropriate Selection of Static and Dynamic Visual and Sound Variables Thematic. Cartography for the Society, Lecture Notes in Geoinformation and Cartography, Springer International Publishing Switzerland, 2014.

Dunston, P. S. Evaluation of augmented reality in steel column inspection. Automation in Construction, 18(2), 118-129, 2009.

Epstein, R. A., Patai, E. Z., Julian, J. B., \& Spiers, H. J. The cognitive map in humans: spatial navigation and beyond. Nature neuroscience, v. 20, n. 11, p. 1504, 2017.

Fabrikant, S. I.; Goldsberry, K. Thematic relevance and perceptual salience of dynamic geovisualization displays. In: Proceedings, 22th ICA/ACI International Cartographic Conference, A Coruña, Spain. 2005.

Griffin A. M.; MacEachren A. M.; Hardisty F.; Steiner E.; Li B. A Comparison of Animated Maps with Static Small-Multiple Maps for Visually Identifying SpaceTime Clusters, Annals of the Association of American Geographers, 96(4), 740-753, 2006.

Google Maps. PlayStore. Available at: https://play.google.com/store/apps/details?id=com.goog le.android.apps.maps. Access in fev., 2021.

Harrower, M. A look at the history and future of animated maps. Cartographica: The International Journal for Geographic Information and Geovisualization, v. 39, n. 3, p. 33-42, 2004.

Harrower, M. The Cognitive Limits of Animated Maps, Cartographica, p. 349-357, 2007.

Harrower M.; Fabrikant, S. The role of map animation for geographic visualization, In Dodge, McDerby, Turner (Eds.), Geographic Visualization, pp. 49-65, London, 2008.

Hillstrom, A. P.; Yantis, S. Visual motion and attentional capture. Attention, Perception, \& Psychophysics, v. 55, n. 4, p. 399-411, 1994

Iida, I. Ergonomia: Projeto e Produção. 2. ed. São Paulo: Edgard Blucher, 2005.

Kraak, M. J. Cartography and the use of animation. In: W. Cartwright, M. P. Peterson, \& G. Gartner, Multimedia Cartography. Berlin: Springer-Verlag, p. 173-180, 1999.

Kraak, M.-J.; Edsall, R. M.; Maceachren, A. M. Cartographic animation and legends for temporal maps: exploration and or interaction. Anais: 18th International Cartography Conference, 253-262, 1997. 
Kraak, M. J. Cartography and the use of animation. In: W. Cartwright, M. P. Peterson, \& G. Gartner, Multimedia Cartography. Berlin: Springer-Verlag, p. 173-180, 1999.

Kraak, M. J., Brown, A., WEB Cartography, Taylor \& Francis, England, 2001.

Krassanakis, V. Exploring the map reading process with eye movement analysis. In: Proceedings of the International Workshop on Eye Tracking for Spatial Research, Scarborough, UK. 2013. p. 2-5.

Laine, T. H. Mobile educational augmented reality games: a systematic literature review and two case studies. Computers, v. 7, n. 1, p. 19, 2018.

Liao, H.; Dong, W.; Peng, C.; Liu, H. Exploring differences of visual attention in pedestrian navigation when using 2D maps and 3D geo-browsers. CAGIS, v. 44, n. 6, p. 474-490, 2017.

Linaza, M. T.; Marimón, D.; Carrasco, P.; Álvarez, R.; Montesa, J.; Aguilar, S. R.; Diez, G. Evaluation of mobile augmented reality applications for tourism destinations. In: Information and communication technologies in tourism 2012. Springer, Vienna, 2012. p. 260-271.

Lobben, A. Classification and application of cartographic animation. The Professional Geographer, v. 55, n. 3, p. 318-328, 2003.

Lochhead, I; Hedley, N. Mixed reality emergency management: bringing virtual evacuation simulations into real-world built environments. International journal of digital earth, v. 12, n. 2, p. 190-208, 2019.

MacEcharen, A. M. Visualizing Uncertain Information. Cartographic Perspectives, Guilford Press, 1995.

MacEachren, A. M.; Dibiase, D. Animated maps of aggregate data: Conceptual and practical problems. Cartography and Geographic Information Systems, v. 18, n. 4, p. 221-229, 1991.

Maps AR - city walk helper. PlayStore. Available at: https://play.google.com/store/apps/details?id=com.thefr enchsoftware.citywalkhelper. Access in fev., 2021.

Mayer, R. E. Multimedia learning. In: Psychology of learning and motivation. Academic Press. p. 85-139, 2002.

Mayer, R. E.; Moreno, R. Nine ways to reduce cognitive load in multimedia learning. Educational psychologist, v. 38, n. 1, p. 43-52, 2003.

Nikander, J.; Järvi, J.; Usman, M.; Virrantaus, K. Indoor and outdoor mobile navigation by using a combination of floor plans and street maps. In: Progress in LocationBased Services. Springer, Berlin, Heidelberg, p. 233-249, 2013.
Opach, T.; Gołębiowska, I.; Fabrikant, S. I. How do people view multi-component animated maps? The Cartographic Journal, v. 51, n. 4, p. 330-342, 2014.

Peterson, M. P. Interactive and animated cartography. 1.ed. New Jersey: Prentice Hall, 1995.

Poole, A.; Ball, L. J.; Phillips, P. In search of salience: A response-time and eye-movement analysis of bookmark recognition. In: People and computers XVIII-Design for life. Springer, London, 2005. p. 363-378.

Pugliesi, E. A.; Decanini, M. M. S.; Ramos, A. P. M.; Tsuchiya, I. Métodos para Avaliação da Usabilidade de Sistemas de Navegação e Guia de Rota. Revista Brasileira de Cartografia. v. 5, n. 65, p. 571-589. 2013.

Radburn, A. A mobile augmented reality demonstrator. Ordonance Survey, 2006.

Ratti, C.; Wang, Y.; Ishii, H.; Piper, B.; Frenchman, D. Tangible User Interfaces (TUIs): a novel paradigm for GIS. Transactions in GIS, v. 8, n. 4, p. 407-421, 2004.

Rauschnabel, P. A.; Rossmann, A.; Tom Dieck, M. C. An adoption framework for mobile augmented reality games: The case of Pokémon Go. Computers in Human Behavior, v. 76, p. 276-286, 2017.

Rohan, A.; Rabah, M.; Kim, S. H. Convolutional neural network-based real-time object detection and tracking for parrot AR drone 2. IEEE, v. 7, p. 69575-69584, 2019.

Scott-Young, S. Seeing the road ahead: Gps-augmented reality aids drivers. GPS World, v. 14, n. 11, 2003.

Shelton, B. E.; Hedley, N. R. Using augmented reality for teaching earth-sun relationships to undergraduate geography students. In: The First IEEE International Workshop Agumented Reality Toolkit. IEEE, 2002. p. 8 pp.

Slocum, A. T.; McMaster, R. B.; Kessler, F. C.; Howard, H. H. Thematic Cartography and Geovisualization. 3rd ed. Prentice Hall, 2009.

Wickens, C. D.; Lee J. D.; Liu Y.; Becker S. G. An Introduction to Human Factors Engineering. 2nd ed. California: Pearson Prentice Hall. p. 608, 2004.

Woods, D. The alarm problem and directed attention in dynamic feault management. Ergonomics, 1995.

Xiaofang, J.; Qiuqun, L.; Yi, W.; Liyan, W.; Jinping, Y.; Hanxiao, Y. Introduction to three-dimensional cochlear medical animation production and application. Computer Era, p. 10, 2014.

Yovcheva, Z.; Buhalis, D.; Gatzidis, C.; Van Elzakker, C. $\mathrm{P}$. Empirical evaluation of smartphone augmented reality browsers in an urban tourism destination context. International Journal of Mobile Human Computer Interaction (IJMHCI), v. 6, n. 2, p. 10-31, 2014. 